\title{
Conserving and managing animals that learn socially and share cultures
}

\author{
HaL WhitehEAD \\ Dalhousie University, Halifax, Nova Scotia, Canada
}

\begin{abstract}
Socially learned behavior can be a crucial factor in how animals interact with their environment and, thus, in conservation and management. For species in which social learning and culture are important determinants of behavior, several factors complicate conservation and management. These include the rapid spread of novel behavior through social learning, the inhibition of adaptive behavior because of cultural conformism, the evolution of maladaptive behavior, and the development of culturally isolated but sometimes sympatric groups. These factors can affect habitat suitability, movements, how animals react to anthropogenic effects, and genetic structures. Social learning and culture may be important factors in translocation success, and should sometimes be considered when delineating population units for conservation and management. We should aim to protect cultural as well as genetic diversity. Unfortunately, clear data on social learning and culture in the wild are scarce. Hence, the ideas and methods outlined in this special issue have great potential.
\end{abstract}

The goal of wildlife conservation is to protect species and their habitats, that of wildlife management to make the exploitation of wild species sustainable (Festa-Bianchet \& Apollonio, 2004). As human pressure on the natural world increases, the conservation and management of wildlife have become more challenging. The better the scientific input into conservation and management, the more effective these are likely to be. This is true at strategic levels (e.g., a regional conservation plan) as well as in the development of tactics (e.g., how we can regulate the exploitation of a particular species whose products have become much more valuable). Of the many scientific inputs that go into conservation and management decisions, the biology of the species themselves is particularly crucial. Behavior is a crucial element of an organism's phenotype and is often the principal way in which it interacts with its inanimate, biological, and social environments. Thus, the ways in which animals behave, as well as the patterns of behavior within and between populations, are often crucial when managing and conserving wildlife (Sutherland, 1998). Both the nature of behavior and the patterning of behavior within the population are dependent on how it is transmitted, whether genetically or through social learning. Socially learned behavior depends on the kind of social learning (imitation, emulation, teaching, experience, etc.) and on the relationship between the learner and the model. For instance, vertically or obliquely transmitted behavior, learned from parents or other elders, tends to be more stable than behavior learned horizontally from peers (Cavalli-Sforza, Feldman, Chen, \& Dornbusch, 1982). As was attested by earlier articles in this issue, social learning has peculiar effects on behavior. It can cause behavior to spread very rapidly through a population or to be highly conserved (Richerson \& Boyd, 2005). It can lead to conformity, maladaptation, ecological success, or ecological disaster. Socially learned group-specific behavior is the essence of culture (Laland, Kendal, \& Kendal, 2009). ${ }^{1}$ Thus, the process of social learning and its productculture-can have major impacts on how animals and their populations interact with humans and, consequently, on how we manage and conserve them.

In this article, I will consider how social leaning and culture can affect some of the principal scientific areas of concern in the conservation and management of wild animals. The section headings reflect these areas. In each section, I will summarize the principal challenges to effective conservation and management and the actual or potential effects of social learning or culture within the target population. Several attributes of social learning and culture are particularly relevant to conservation and management.

Rapid spread of novel behavior through social learning. Theoreticians often consider that social learning evolved as a less expensive and time-consuming manner of obtaining information that would otherwise be gathered by individual learning (e.g., Boyd \& Richerson, 1985). Thus, through social learning, most individuals adopt new behavior more quickly than if they had to discover it themselves, and some acquire behavior that they would not have discovered independently. Hence, social learning speeds the spread of behavior through a population and may lead to its performance by a larger proportion of the population than would be expected through individual learning.

Inhibition of the acceptance of novel behavior through cultural conformism. In a diverse population, 
selecting which behavior to learn socially is important and potentially difficult. A shortcut that may work well is to adopt the behavior of the majority of the population - to conform (Henrich \& Boyd, 1998). This can be exacerbated by cultures of conformity - when conforming becomes an important marker of group identity, inhibiting the adoption of adaptive behavior.

Maladaptive behavior. As Richerson and Boyd (2005) argued cogently, culture may promote behavior in individuals that is not in the interests of their genes. Such behavior will also be generally bad for the population. This happens because animals may learn socially from nonrelatives (who do not have a common genetic interest), because mechanisms for restricting social learning to genetically adaptive content are too costly, because generally adaptive psychological mechanisms such as conformism and prestige bias (learning preferentially from a subset of individuals considered prestigious) lead to the spread of maladaptive side effects, and because maladaptive cultural ideas can evolve much more quickly than genetic selection can counter them (Richerson \& Boyd, 2005).

Division of population into groups with distinct cultures, which may be sympatric. Social learning may lead to culture - to behavioral patterns that are distinctive of groups of animals (Laland et al., 2009). When these patterns cause social or reproductive isolation, as in courtship signals that are not effective across groups, this segments the population in ways that are important to both management and conservation (Laiolo, 2008). Generally, wildlife managers and conservationists consider themselves to be managing or conserving one or more collections of animals, which can be called populations, stocks, or units, each mapped onto a particular geographical area. However, social learning - especially conformist social learning - can lead to culturally distinct groups using the same area, with few social or reproductive connections between them (for instance, in the killer [Orcinus orca] and sperm [Physeter macrocephalus] whales discussed later). When this occurs, conservation and management cannot be purely geographically based but should also consider the cultural divisions in the population (Logan \& Pepper, 2007; Whitehead, Rendell, Osborne, \& Würsig, 2004).

\section{Habitat Suitability and Variability in Space and Time}

For a population to prosper, it must have a suitable habitat, with suitability being a function of the animals' phenotypes and especially their behavior. Habitat suitability naturally varies in space and time, and this variability may be enhanced by anthropogenic influences. Temporal variability in habitat suitability is a challenge to members of any population. Spatial variability can be used to compensate for this, via moving adaptively between habitats as conditions change. Social learning can be an important way in which animals adopt effective movement strategies (e.g., guppies, Poecilia reticulata; Morrell et al., 2008). Additionally, social learning can change an animal's niche space and thus its conception of suitable habitat-for instance, if it learns of new foods or feeding techniques from conspecifics (Ramsey, Bastian, \& van Schaik, 2007).
Thus, social learning can assist the viability of populations affected by variable habitats. However, conformist cultures can inhibit adaptive learning, with useful behavior not being adopted or potentially valuable habitats not being explored because they lie outside the animals' cultural norms. For instance, although the killer whale as a species has a wide niche breadth, types, pods, and other segments of the species use just a few culturally determined prey species. The southern resident population specializes on chinook salmon (Oncorhynchus tshawytscha), and its population status is highly dependent on the health of the chinook stock (Ford \& Ellis, 2006). Although these animals can physiologically subsist on many other species, they seem extremely reluctant to use them. This conformist behavior is a constraint on the resilience of the southern residents in the face of naturally and anthropogenically caused variation in chinook abundance.

Although social learning and culture can influence the suitability of habitats both positively and negatively, attributes of habitats may make them suitable or unsuitable for important cultural traits on which animals depend. For instance, Laiolo (2008) examined variation in the songs of Dupont's lark (Chersophilus duponti) in a fragmented habitat. The cultural song traditions of populations occupying the smallest patches appeared to have eroded. If the diversity of song, or other socially learned behavior, is functional, the animals in the small patches may have lower fitness. Thus, the viability of a population may be indicated by patterns in spatial cultural variability (Laiolo, 2008).

\section{Exploiting Anthropogenic Change}

Although there is a great deal of concern about whether species can survive anthropogenic change to their environments, another suite of problems may be introduced by how the animals deal with human effects. Some species have learned to use resources that are a by-product of human presence. In some cases - for instance, that of bottlenose dolphins (Tursiops sp.) feeding from trawler discards (Chilvers \& Corkeron, 2001) - the relationship is basically commensal with no major perceived positive or negative effects on humans. But in other cases, the new behavior may make the animals become pests or dangers. Examples of animal exploitation of human presence that is generally perceived negatively and may be spread through social learning include fish depredation from long lines by killer and sperm whales (Whitehead et al., 2004); crop raiding by African elephants, Loxodonta africana (Osborn, 2002) or chimpanzees, Pan troglodytes (McGrew, 2004); the use of anthropogenic food by black bears, Ursus americanus (Mazur \& Seher, 2008); and man-eating by tigers, Panthera tigris (Kitchener, 1999).

Whether the new behavior is learned socially has a major impact on how fast it spreads: Social learning will generally greatly speed population acquisition. By increasing the rate of uptake and extent of these activities within the population, social learning exacerbates the negative effects for humans and the potential ramifications (shooting, calls for culls, exposure to disease organisms, etc.) on the animals. The presence of social learning in the 
spread of the behavior should be an important factor in the management of such issues. Although, to my knowledge, social learning is rarely considered explicitly, attempts might be made to disrupt patterns of social transmission of unwanted behavior or to enhance those of desired behavior. For instance, the translocation of problem animals may be a poor idea if naive animals in the destination area then learn the behavior.

\section{Culture and Climate Change}

There is considerable evidence that climate change is affecting animal populations and their diversity, so that questions about climate change are at the forefront of the concerns of conservation biologists (Sutherland et al., 2009). As environments change, both naturally and anthropogenically, phenotypic diversity generally promotes population resilience. Thus, we value genetic diversity. But when social learning is an important driver of behavior, cultural diversity is also important (Whitehead et al., 2004). In fact, several scientists have suggested and shown using models that adapting to environmental change may have driven the evolution of cultural capacity in humans (Boyd \& Richerson, 1985) and other species (Whitehead, 2007). Thus, species in which social learning drives cultural variability in behavior may be naturally better equipped to deal with climate change. This could particularly be the case for those species that use cultural niche construction (Laland \& Brown, 2006) to counteract environmental pressures. Such species will generally be less anatomically adapted to and dependent on any one environment and will thus be able to cope better when that environment changes. A proviso here is that strongly conformist cultures may inhibit adaptive change in behavior (as was noted in the introduction).

As an example, consider the sperm whale in the eastern tropical Pacific. The population is divided into clans, which possess distinctive dialects (Rendell \& Whitehead, 2003). The clans are large, with thousands of members, and sympatric, with about two or three clans using any area. The clans show little or no differences in their nuclear DNA (as indicated by microsatellites), and the primary differences between them are cultural (Whitehead, 2003). The clans differ in their communicative sound patterns, but also in their movement patterns and feeding success (Whitehead \& Rendell, 2004). Off the Galapagos Islands, there are two main clans. In normal years, the regular clan has higher feeding success, but during a warm El Niño year, when all of the animals showed greatly reduced feeding success, the plus-one clan consistently fed better. The clans also show evidence for differences in reproductive success (Marcoux, Rendell, \& Whitehead, 2007), and since global warming may in some ways mimic El Niño, the cultural diversity of this species as represented by the different clans is likely to be important as oceans warm.

\section{Dispersal, Migration, and Movement}

Space is an important resource for many animals, and almost all of the other resources on which animals depend are spatially variable. Thus, dispersal, migration, and movement are vital elements of an animal's pheno- type, with huge effects on fitness. It seems likely that, in many species, the use of space is socially learned. This can happen over a range of scales. When a few months old, a young humpback whale (Megaptera novaeangliae) follows his or her mother thousands of kilometers from the tropical winter calving grounds to temperate summer feeding grounds and then uses the same grounds and, presumably, the same migration route between them over its lifetime (Stevick, McConnell, \& Hammond, 2002). Over smaller scales, it is suggested that cat sharks (Scyliorhinus canicula) learn daily movement patterns socially (Guttridge, Myrberg, Porcher, Sims, \& Krause, 2009), and juvenile marsh harriers (Circus aeruginosus) seem to select habitat patches where there is greater access to prey if they hunt with adults and other juveniles than if they hunt individually (Kitowski, 2009).

Such movement strategies are crucial elements of the adaptive phenotype of the population. There is a concern that when populations are brought to very low levels, some of this cultural information is lost, just as genetic variability is lost in population bottlenecks. For instance, it has been argued that the very simple technological culture of the aboriginal Tasmanians results from their isolation and small population size over many generations (McGrew, 1987). Similarly, Whitehead et al. (2004) suggested that the inability of the North Atlantic right whale (Eubalaena glacialis) population to rebuild from just a few hundred animals after whaling may be partially due to loss of information about suitable habitats. Right whales are now found consistently in only a few of the areas in which they were traditionally hunted, and the health of the population seems to depend substantially on the availability of food in just one area, the Gulf of Maine (Hlista, Sosik, Traykovski, Kenney, \& Moore, 2009). Traditional knowledge of alternative feeding areas may have been lost, leaving the population with less resilience in years when conditions in the Gulf of Maine area are poor.

Cultural conformism may restrict animals' adaptive use of space. For instance, Osborne (1999) suggested that killer whales may keep using traditional areas even though they are now heavily polluted chemically or by noise and it would be better to avoid these noxious conditions.

\section{Adaptive Behavior and Population Viability}

Within species-specific constraints, evolutionary biologists generally assume that behavior will evolve to optimize fitness. Although this may generally be true over multigenerational time periods and with large populations, conservation and management typically concern time periods of no more than a generation or two and small populations in which differences between the behavior of individual animals may be very significant. In addition, behavior that maximizes individual fitness may not necessarily promote population viability-for instance, if it involves costly displays (Møller, 2000).

For these reasons, in recent years, wildlife biologists have started to use individual-based models to examine the potential short- and long-term effects of management decisions on small populations consisting of individuals with variable phenotypes, which may include individual 
variation in behavior (Gosling, 2004). Because social learning and culture can have profound effects on the behavior of a population, management/conservation models for such populations - whether heuristic, algebraic, or numerical-need very different forms. Such models need to include not only the social transmission of phenotypic information, but also any constraints on social learning. For instance, there may be a developmental window in which social learning of certain traits occurs; one sex or the other may ignore social information; and only certain individuals may be attended to (van de Waal, Renevey, Favre, \& Bshary, in press).

As an example, McComb, Moss, Durant, Baker, and Sayialel (2001) showed that the level of knowledge was higher and the behavior more adaptive in African elephant groups that were led by older matriarchs. These groups had generally higher reproductive success. Poachers preferentially take larger animals with bigger tusks, who tend to be older. Since these animals have greater knowledge, the effect of the poaching on population viability is much more substantial than simply the number of animals killed.

As another, broader example, Whitehead and Richerson (2009) showed how the evolution of conformist social learning in red-noise environments can lead to population collapse as individuals pay attention only to each others' behavior, losing track of the environmental optimum. A red-noise environment is one dominated by low-frequency variation - for instance, of temperature, rainfall, or prey abundance. With red noise, the environment tends to remain fairly stable over short periods, promoting the evolution of conformist social learning, but can change very considerably over longer spans, at which time conformism is dangerous, since the individuals pay attention to each other rather than periodically sampling the altered underlying environment for themselves. Whitehead and Richerson suggested that this phenomenon may explain the collapse or extirpation of several human societies but also noted that it could be applicable to nonhuman populations with conformist cultures.

\section{Translocation and Reintroduction}

Translocation and reintroduction are important-if sometimes controversial - techniques in wildlife conservation (Kleiman, 1989). Animals are moved into an area in the wild. These can be captive animals or animals from a wild population somewhere else. The destination may be an area from which the species has been extirpated or brought to very low numbers or a new habitat (an introduction) that appears suitable for a species whose traditional habitat has become largely untenable. Reasons for moving the animals include trying to reestablish a species that is extinct or at very low numbers in the wild, restoring natural ecosystems, providing hunting opportunities, and attempting to increase the survival prospects of a species threatened with habitat destruction or habitat change (e.g., logging or climate change).

Translocation and reintroduction programs have had very mixed success (Owen-Smith, 2003). Failures have often been blamed on unsuitable habitat or predators. Owen-Smith noted that learning plays a major role in the ability of animals to adapt to their new environments. The speed with which they adapt is important. The faster the animals learn, the more likely it is that the population will survive and grow. Social learning is an important way of learning about a new environment and learning about it faster than if each animal has to discover the characteristics individually.

One of the most successful and well-studied cases of reintroduction is that of the Arabian oryx (Oryx leucoryx), which were returned to Oman from a captive population 10 years after their extinction in the wild. Tear, Mosley, and Ables (1997) examined the foraging decisions of the reintroduced animals and suggested that learning was an important factor in the development of the reintroduced animals' foraging patterns. They also concluded that social learning is likely an element of the foraging strategies of oryx and thus of the success of this reintroduction.

Griffin, Blumstein, and Evans (2000) and Griffin (2004) suggested that social learning may be a useful way to train animals that are about to be translocated or reintroduced to avoid predators. Custance, Whiten, and Fredman (2002, p. 481) went further: "The most direct application of social learning research to primate conservation appears to be as a method for skill training in preparation for reintroduction." In order to improve the adaptive behavior of reintroduced animals, a successfully reintroduced individual might be added to a naive group on release. Following this, Custance et al. examined studies of social learning in primates, hoping to gain insight into whether such a strategy might be successful and how its success might be optimized. Unfortunately, they found rather little useful information, partly because studies of social learning in primates were more oriented toward mechanisms than toward function.

There is more optimism with fish. Brown and Laland (2001) suggested that the manipulation of social learning in captivity might improve the viability of hatchery-raised fish in the wild, thus enhancing the population in the wild. An experimental study by Vilhunen, Hirvonen, and Laakkonen (2004) showed the efficacy of social learning as a way to improve antipredator behavior in Saimaa Arctic char (Salvelinus alpinus). In contrast to expectations from theory, the naive fish learned better with a relatively small proportion of experienced fish.

When a small population is to be augmented by translocated individuals, it may be crucially important that the new individuals possess some of the cultural norms of the natives, whether these norms are ecologically adaptive for the habitat or affect social relationships, such as courtship (Ryan, 2006). If there is no extant native population, it still may be important that the introduced animals possess the same cultural norms if they are to form a cohesive population.

In reintroduction from captivity, we need to be aware of relaxed selection and loss of cultural diversity that is adaptive to the wild, but also the inception of traditions among captive animals that, although adaptive in captiv- 
ity, are maladaptive in the wild (e.g., tolerance of humans or extreme boldness). Through the link with heritable temperaments, these factors may also affect genetic diversity (McDougall, Réale, Sol, \& Reader, 2006).

\section{Exploitation Systems}

The traditional science behind the management of the exploitation of wildlife - whether legal or illegal-assumes that members of a population are identical in their behavior and that there are no systematic changes in behavior over time. These are clearly unrealistic assumptions in many cases. Age-structured and stage-structured models that allow phenotypic characteristics to change over an individual's lifetime represented a major advance in realism and, thus, in the ability to manage exploitative systems effectively (Tuljapurkar \& Caswell, 1997). However, social learning and culture can add dimensions to a population's phenotypic diversity that are not captured by such age- or stage-structured models, and these dimensions may affect the ways in which exploitation affects a population.

For instance, if individuals socially learn methods of avoiding capture, the rate of capture per unit effort, a commonly used metric of population size, will decline more quickly than the population itself. Likewise, in a population that is culturally structured so that different cultural entities possess behavior making them more or less likely to be caught, the more easily captured animals will be caught first, and then the catch per unit effort will decline more quickly than the decline in population size, since the remaining animals are more elusive. Smith, Reeves, Josephson, Lund, and Whitehead (2008) explored this effect as a potential explanation of the sperm whale paradox, in which the sightings per unit effort of sperm whales in the 19th century declined more quickly than the rate at which the population could have reasonably been reduced (since it survived a much heavier catch in the 20th century). In both of these situations, the effects of exploitation will be overestimated by catch per unit effort methods, making management conservative.

However, if animals use social learning to optimize their habitat use (for instance, by following others or using cues provided by others), this can contribute to densitydependent habitat selection, in which the density of animals in any habitat is proportional to its value (MacCall, 1990). Density-dependent habitat selection tends to make exploitation appear less serious than it is (hyper-depletion), because the population will decline more quickly than the rate of catch in the best habitat, where the population is increasingly concentrated and where the exploiters concentrate their resources.

\section{Genetic Structure}

Culture and genetics can be considered alternative inheritance systems, either or both potentially affecting behavior. However, through their influence on phenotype, genes and culture can affect each other (Richerson \& Boyd, 2005). In particular, culture can drive patterns of gene flow, which may have implications for management and conservation.
Ryan (2006) considered cases in which culture affects patterns of reproduction, leading to reproductively isolated population segments, which may be significant for management and conservation. Socially learned bird vocalizations can form a patchwork of regional dialects and can lead to social or reproductive exclusion if individuals travel into areas in which their own repertoire is not recognized (Laiolo, 2008). Conservation biologists may wish to preserve this cultural diversity per se, because it can become a significant evolutionary force, perhaps even leading to speciation (Slabbekoorn \& Smith, 2002). The barriers to movement produced by culture can become important factors in how the birds respond to anthropogenic threats. In situations like this, culture needs to become an important element of management instruments (see below).

\section{Maladaptive Behavior}

Social learning can sometimes spread maladaptive behavior. For instance, chimpanzees at Bossou pound the crowns of oil palms with detached fronds to make a rich, pulpy soup, but this may endanger the health of the palms (McGrew, 2003) and, thus, the resource base for the chimpanzee population. This destructive behavior is spread by social learning, as are many other activities that have long-term negative implications for a population, such as the use of anthropogenic food by bears (Mazur \& Seher, 2008). Social learning is not, however, at the heart of the behavior's destructiveness; it exacerbates the problem by increasing the rate at which it is spread and its incidence within the population.

However, culture-especially conformist culture - can actually lead to maladaptive behavior, as is very obvious in humans (Richerson \& Boyd, 2005; see the introduction) and has been shown for captive guppies (Laland \& Williams, 1998). There is no concrete evidence that conformism leads to maladaptive behavior among nonhumans in the wild (Perry, 2009), although the mass strandings of groups of whales and dolphins may be linked to their conformist cultures (Rendell \& Whitehead, 2001). Populations in which conformist culture produces such maladaptive effects have withstood them naturally over time. The principal concern for conservation is that anthropogenic influences might increase the frequency or severity of maladaptive events - for instance, if undersea noise increased the frequency of mass strandings of cetaceans (see Weilgart, 2007). Secondarily, natural culturally induced maladaptive behavior might be confused with anthropogenic disturbance, leading to the misdirection of conservation efforts (Whitehead et al., 2004).

\section{Management/Conservation Instruments}

One of the more difficult decisions facing both wildlife managers and conservation biologists is how to define the populations that they manage and conserve. In wildlife management, these are often called stocks; in conservation biology, terminology is various and somewhat fraught (populations, species, designatable units, etc.). However, a variety of theoretical contributions have suggested that 
what we should be trying to conserve are evolutionarily significant units, or ESUs. Defining the ESU has proved difficult. It is felt that ESUs should be delineated to preserve both adaptive variation in genes and phenotypes and evolutionary divergence caused by isolation over time and/ or space (e.g., de Guia \& Saitoh, 2007). The emphasis has generally been on using genetic data to distinguish ESUs (e.g., Ryan, 2006). However, when important phenotypic variance is culturally determined, then, as both Whitehead et al. (2004) and Ryan argued, this should be considered. Ryan suggested the delineation of culturally significant units (CSUs), complementary to ESUs. Whitehead et al. proposed defining ESUs so that they could incorporate both cultural and genetic effects. For instance, they modify Fraser and Bernatchez's (2001, p. 2747) ESU definition to become a "lineage demonstrating highly restricted flow of information that determines phenotypes from other such lineages within the higher organizational level (lineage) of the species."

Cultural issues will quite rarely be important in the delineation of management/conservation populations. Cultural variation in behavior is likely not significant for many species, and when it is, it may covary with genetic differences that can be used to define stocks or ESUs. However, sometimes culture uniquely —or predominantly — distinguishes groups of animals that use their environments quite differently. For instance, consider the bottlenose dolphins of Moreton Bay, Australia. The several hundred dolphins that use the bay form two communities: one that feeds extensively off trawler discards and one that does not (Chilvers \& Corkeron, 2001). Members of the two communities have overlapping ranges but rarely socialize, except for possibly some mating (Chilvers \& Corkeron, 2001). Clearly, management of the trawl fishery needs to take this almost certainly cultural delineation into consideration. The use of trawler discards can be thought of as a form of cultural niche modification/construction (Laland, Odling-Smee, \& Feldman, 2000). Ryan (2006) noted that niche modification may emphasize the importance of delineating and protecting critical habitat defined purely on cultural grounds.

A case can also be made that culture should be used to define ESUs or CSUs for the cultural clans of eastern tropical Pacific sperm whales, which, as was noted above, respond differently to environmental change (Whitehead et al., 2004). However, the major instance in which culture has been invoked in population delineation is that of the killer whales off the west coast of North America. There are three very different types of killer whale using these waters. They eat different foods and may be real or incipient subspecies. Most well known is the fish-eating resident type. The resident population is divided into communities, between which there is little or no dispersal or mating, although community ranges do somewhat overlap. Genetic differences between the communities are few but consistent, whereas cultural differences (in vocalizations, social behavior, and ranging behavior) are substantial (Barrett-Lennard, Deecke, Yurk, \& Ford, 2001; Ford, Ellis, \& Balcomb, 2000). Animals of the southern resident community, numbering less than 100 , range across the
U.S.-Canadian border. The Canadian government, noting the distinctiveness of the southern residents from other killer whales and their small population size and threats, designated them separately from other killer whales as endangered. However, the U.S. National Marine Fisheries Service initially rejected the cultural evidence, concluding that the southern residents were not a "distinct population segment," and lumped the southern residents with other killer whales (Teaney, 2004). After protests, this decision was reversed in 2005, and the southern residents were designated as endangered in the U.S., as they had been in Canada.

\section{Perception of Species}

Ultimately, the decisions that allow species to persist or to sustain healthy populations are not made by scientists (Festa-Bianchet \& Apollonio, 2004). They are made by politicians and managers. The advice of wildlife biologists is only one of the factors that they juggle in deciding how to act. In democratic societies, and to a lesser extent in undemocratic ones, politicians respond to perceptions of the public will. Evidence for social learning and especially culture can affect how the public perceives a particular species (Custance et al., 2002; Laiolo \& Jovani, 2007) and, thus, the likelihood that their political representatives will make effective conservation and management decisions. Fox (2001, p. 333) argued that the cultural attributes of cetaceans and primates indicate that they "share with humans a common extended moral community" and should hence receive particular protection.

Conservation and management are about affecting human behavior. Humans are the supreme social learners and cultural animals. Therefore, effective protection and maintenance of wildlife needs an understanding of social learning in humans in order to enhance transmission of the conservation message, both in particular cases, such as the value of a wildlife preserve, and with more general issues such as global warming and pollution. Thus, conservation science is a social science (Mascia et al., 2003).

\section{Conclusion}

In wildlife management and conservation, a fundamental goal is preservation of diversity - diversity of form and perhaps especially diversity in the range of ecosystem services that the wildlife provides (Luck, Daily, \& Ehrlich, 2003). Cultures may form important elements of this diversity (Whitehead et al., 2004), and thus, as has been repeatedly argued for human cultural elements such as languages and architecture, cultural diversity should be conserved as a principle. There is an argument that conservation should be particularly focused and management particularly careful for some species because of their cultural diversity, as well as the correlates and the consequences of their cultural capacity.

When conserving or managing a small population or small populations of a species for which social learning and the resultant culture are important, there are two potential strategies (Ryan, 2006): We can try to protect the cultural diversity that exists or maintain a sufficient population size so that social learning can reestablish an effec- 
tive level of cultural diversity. We have no idea what this minimum number is, although arguments have been made that persistently small human populations lose cultural diversity (Diamond, 1978). Thus, the emphasis should generally be on preserving extant cultural processes and diversity (Ryan, 2006).

In addition, I have argued that social learning and culture are likely to be important factors in the hands-on conservation and management of some wild species and their ecosystems. It follows that to conserve and manage effectively, we need to know how social learning operates, as well as the role of cultures, among animals in the wild. To date, social learning has proved hard to study in the wild, and the evidence for cultures of wild animals is hotly debated (Laland \& Janik, 2006). The ideas and methods described in the other articles of this issue will be of immense value in this respect.

\section{AUTHOR NOTE}

Thanks to Lance Barrett-Lennard for discussion on the format of the article and to Rachel Kendal and an anonymous reviewer for many suggestions that improved the manuscript. Correspondence concerning this article should be addressed to H. Whitehead, Department of Biology, Dalhousie University, 1355 Oxford St., Halifax, Nova Scotia, B3H 4J1 Canada (e-mail: hwhitehe@dal.ca).

\section{REFERENCES}

Barrett-Lennard, L. G., Deecke, V. B., Yurk, H., \& Ford, J. K. B. (2001). A sound approach to the study of culture. Behavioral \& Brain Sciences, 24, 325-326.

BOyd, R., \& Richerson, P. J. (1985). Culture and the evolutionary process. Chicago: Chicago University Press.

Brown, C., \& LaLAND, K. N. (2001). Social learning and life skills training for hatchery reared fish. Journal of Fish Biology, 59, 471-493.

Cavalli-Sforza, L. L., Feldman, M. W., Chen, K. H., \& Dornbusch, S. M. (1982). Theory and observation in cultural transmission. Science, 218, 19-27.

Chilvers, B. L., \& Corkeron, P. J. (2001). Trawling and bottlenose dolphins' social structure. Proceedings of the Royal Society B, 268, 1901-1905.

Custance, D. M., Whiten, A., \& Fredman, T. (2002). Social learning and primate reintroduction. International Journal of Primatology, 23, 479-499.

DE Guia, A. P. O., \& Saitoh, T. (2007). The gap between the concept and definitions in the evolutionarily significant unit: The need to integrate neutral genetic variation and adaptive variation. Ecological Research, 22, 604-612.

DiAmond, J. M. (1978). The Tasmanians: The longest isolation, the simplest technology. Nature, 273, 185-186.

Festa-Bianchet, M., \& APOLlonio, M. (2004). General introduction. In M. Festa-Bianchet \& M. Apollonio (Eds.), Animal behavior and wildlife conservation (pp. 3-11). Washington, DC: Island Press.

ForD, J. K. B., \& ElLIs, G. M. (2006). Selective foraging by fish-eating killer whales Orcinus orca in British Columbia. Marine Ecology Progress Series, 316, 185-199.

Ford, J. K. B., Ellis, G. M., \& Balcomb, K. C., III (2000). Killer whales: The natural history and genealogy of Orcinus orca in British Columbia and Washington State (2nd ed.). Vancouver: UBC Press.

Fox, M. A. (2001). Cetacean culture: Philosophical implications. Behavioral \& Brain Sciences, 24, 333-334.

Fraser, D. J., \& Bernatchez, L. (2001). Adaptive evolutionary conservation: Towards a unified concept for defining conservation units. Molecular Ecology, 10, 2741-2752.

GosLING, L. M. (2004). Adaptive behavior and population viability. In M. Festa-Bianchet \& M. Apollonio (Eds.), Animal behavior and wildlife conservation (pp. 13-30). Washington, DC: Island Press.
GrifFIN, A. S. (2004). Social learning about predators: A review and prospectus. Learning \& Behavior, 32, 131-140.

Griffin, A. S., Blumstein, D. T., \& Evans, C. S. (2000). Training captive-bred or translocated animals to avoid predators. Conservation Biology, 14, 1317-1326.

Guttridge, T. L., Myrberg, A. A., Porcher, I. F., Sims, D. W., \& Krause, J. (2009). The role of learning in shark behaviour. Fish \& Fisheries, 10, 450-469.

HENRICH, J., \& BOYD, R. (1998). The evolution of conformist transmission and the emergence of between-group differences. Evolution \& Human Behavior, 19, 215-241.

Hlista, B. L., SosiK, H. M., Traykovski, L. V. M., Kenney, R. D., \& Moore, M. J. (2009). Seasonal and interannual correlations between right-whale distribution and calving success and chlorophyll concentrations in the Gulf of Maine, USA. Marine Ecology Progress Series, 394, 289-302.

Kitchener, A. C. (1999). Watch with mother: A review of social learning in the Felidae. In H. O. Box \& K. R. Gibson (Eds.), Mammalian social learning: Comparative and ecological perspectives (pp. 236258). Cambridge: Cambridge University Press.

KITOWSKI, I. (2009). Social learning of hunting skills in juvenile marsh harriers Circus aeruginosus. Journal of Ethology, 27, 327-332.

KLEIMAN, D. G. (1989). Reintroduction of captive mammals for conservation. Bioscience, 39, 152-163.

LAIOLO, P. (2008). Characterizing the spatial structure of songbird cultures. Ecological Applications, 18, 1774-1780.

Laiolo, P., \& Jovani, R. (2007). The emergence of animal culture conservation. Trends in Ecology Evolution, 22, 5.

Laland, K. N., \& Galef, B. G., JR. (Eds.) (2009). The question of animal culture. Cambridge, MA: Harvard University Press.

Laland, K. N., \& BRown, G. R. (2006). Niche construction, human behavior, and the adaptive-lag hypothesis. Evolutionary Anthropology, 15, 95-104.

LALAND, K. N., \& JANIK, V. M. (2006). The animal cultures debate. Trends in Ecology \& Evolution, 21, 542-547.

Laland, K. N., Kendal, J. R., \& Kendal, R. L. (2009). Animal culture: Problems and solutions. In K. N. Laland \& B. G. Galef, Jr. (Eds.), The question of animal culture (pp. 174-197). Cambridge, MA: Harvard University Press.

Laland, K. N., Odling-Smee, J., \& Feldman, M. W. (2000). Niche construction, biological evolution and cultural change. Behavioral \& Brain Sciences, 23, 131-146.

Laland, K. N., \& Williams, K. (1998). Social transmission of maladaptive information in the guppy. Behavioral Ecology, 9, 493-499.

Logan, C. J., \& PePper, J. W. (2007). Social learning is central to innovation, in primates and beyond. Behavioral \& Brain Sciences, 30, 416-417.

Luck, G. W., Daily, G. C., \& Ehrlich, P. R. (2003). Population diversity and ecosystem services. Trends in Ecology \& Evolution, 18, 331-336.

MACCALL, A. D. (1990). Dynamic geography of marine fish populations. Seattle: Washington Sea Grant/University of Washington Press.

Marcoux, M., Rendell, L., \& Whitehead, H. (2007). Indications of fitness differences among vocal clans of sperm whales. Behavioural Ecology \& Sociobiology, 61, 1093-1098.

Mascia, M., Brosius, J. P., Dobson, T. A., Forbes, B. C., Horowitz, L., McKean, M. A., \& Turner, N. J. (2003). Conservation and the social sciences. Conservation Biology, 17, 649-650.

MAzur, R., \& SEHER, V. (2008). Socially learned foraging behaviour in wild black bears, Ursus americanus. Animal Behaviour, 75, 15031508.

McComb, K., Moss, C., Durant, S. M., Baker, L., \& Sayialel, S. (2001). Matriarchs as repositories of social knowledge in African elephants. Science, 292, 491-494.

McDougall, P. T., Réale, D., Sol, D., \& Reader, S. M. (2006). Wildlife conservation and animal temperament: Causes and consequences of evolutionary change for captive, reintroduced, and wild populations. Animal Conservation, 9, 39-48.

McGrew, W. C. (1987). Tools to get food: The subsistants of Tasmanian aborigines and Tanzanian chimpanzees compared. Journal of Anthropological Research, 43, 247-258.

McGrew, W. C. (2003). Ten dispatches from the chimpanzee culture wars. In F. B. M. de Waal \& P. L. Tyack (Eds.), Animal social complex- 
ity: Intelligence, culture, and individualized societies (pp. 419-439). Cambridge, MA: Harvard University Press.

McGrew, W. C. (2004). The cultured chimpanzee: Reflections on cultural primatology. Cambridge: Cambridge University Press.

MøLLER, A. P. (2000). Sexual selection and conservation. In L. M. Gosling \& W. J. Sutherland (Eds.), Behavior and conservation (pp. 161171). Cambridge: Cambridge University Press.

Morrell, L., Croft, D. P., Dyer, J., Chapman, B., Kelley, J., LaLAND, K. N., \& Krause, J. (2008). Association patterns and foraging behaviour in natural and artificial guppy shoals. Animal Behaviour, 76, 855-864.

OsBorn, F. V. (2002). Capsicum oleoresin as an elephant repellent: Field trials in the communal lands of Zimbabwe. Journal of Wildlife Management, 66, 674-677.

Osborne, R. W. (1999). A historical ecology of Salish Sea "resident" killer whales (Orcinus orca): With implications for management. Unpublished doctoral dissertation, University of Victoria, Victoria, British Columbia.

Owen-Smith, N. (2003). Foraging behavior, habitat suitability, and translocation success, with special reference to large mammalian herbivores. In M. Festa-Bianchet \& M. Apollonio (Eds.), Animal behavior and wildlife conservation (pp. 93-109). Washington, DC: Island Press.

PerRy, S. (2009). Are non-human primates likely to exhibit cultural capacities like those of humans? In K. N. Laland \& B. G. Galef, Jr. (Eds.), The question of animal culture (pp. 247-268). Cambridge, MA: Harvard University Press.

Ramsey, G., Bastian, M. L., \& van Schaik, C. (2007). Animal innovation defined and operationalized. Behavioral \& Brain Sciences, 30, 393-407.

Rendell, L. E., \& Whitehead, H. (2001). Culture in whales and dolphins. Behavioral \& Brain Sciences, 24, 309-324.

RENDELL, L. E., \& WhiteHEAD, H. (2003). Vocal clans in sperm whales (Physeter macrocephalus). Proceedings of the Royal Society B, 270, 225-231.

Richerson, P. J., \& Boyd, R. (2005). Not by genes alone: How culture transformed human evolution. Chicago: Chicago University Press.

RYAN, S. J. (2006). The role of culture in conservation planning for small or endangered populations. Conservation Biology, 20, 1321-1324. doi:10.1111/j.1523-1739.2006.00347.x

SlabbeKoorn, H., \& Smith, T. B. (2002). Bird song, ecology and speciation. Philosophical Transactions of the Royal Society B, 357, 493-503.

Smith, T. D., Reeves, R. R., Josephson, E. A., Lund, J. N., \& WhiteHEAD, H. (2008). Sperm whale catches and encounter rates during the 19th and 20th centuries: An apparent paradox. In D. J. Starkey \& M. Barnard (Eds.), Oceans past: Management insights from the history of marine animal populations (pp. 149-173). London: Earthscan/ James \& James

Stevick, P. T., McConnell, B. J., \& Hammond, P. S. (2002). Patterns of movement. In A. R. Hoelzel (Ed.), Marine mammal biology: An evolutionary approach (pp. 185-216). Oxford: Blackwell.
SutherLAND, W. J. (1998). The importance of behavioural studies in conservation biology. Animal Behaviour, 56, 801-809.

Sutherland, W. J., Adams, W. M., Aronson, R. B., Aveling, R., Blackburn, T. M., Broad, S., et Al. (2009). One hundred questions of importance to the conservation of global biological diversity. Conservation Biology, 23, 557-567.

Teaney, D. O. (2004). The insignificant killer whale: A case study of inherent flaws in the wildlife services' distinct population segment policy and a proposed solution. Environmental Law, 34, 647-702.

Tear, T. H., Mosley, J. C., \& Ables, E. D. (1997). Landscape-scale foraging decisions by reintroduced Arabian oryx. Journal of Wildlife Management, 61, 1142-1154.

TulJaPurkar, S., \& CASWell, H. (1997). Structured-population models in marine, terrestrial, and freshwater systems. New York: Chapman \& Hall.

van de WaAl, E., Renevey, N., Favre, C. M., \& Bshary, R. (in press). Selective attention to philopatric models causes directed social learning in wild vervet monkeys. Proceedings of the Royal Society B. doi:10.1098/rspb.2009.2260

Vilhunen, S., Hirvonen, H., \& LaAkKonen, M. V. M. (2004). Less is more: Social learning of predator recognition requires a low demonstrator to observer ratio in Arctic charr (Salvelinus alpinus). Behavioral Ecology \& Sociobiology, 57, 275-282.

WeILGaRT, L. S. (2007). The impacts of anthropogenic noise on cetaceans and implications for management. Canadian Journal of Zoology, 85, 1091-1116.

Whitehead, H. (2003). Sperm whales: Social evolution in the ocean. Chicago: Chicago University Press.

WhITEHEAD, H. (2007). Learning, climate and the evolution of cultural capacity. Journal of Theoretical Biology, 245, 341-350.

Whitehead, H., \& Rendell, L. (2004). Movements, habitat use and feeding success of cultural clans of South Pacific sperm whales. Journal of Animal Ecology, 73, 190-196.

Whitehead, H., Rendell, L., Osborne, R. W., \& WÜRsig, B. (2004). Culture and conservation of non-humans with reference to whales and dolphins: Review and new directions. Biological Conservation, 120, 427-437.

Whitehead, H., \& Richerson, P. J. (2009). The evolution of conformist social learning can cause population collapse in realistically variable environments. Evolution \& Human Behavior, 30, 261-273.

\section{NOTE}

1. Although some definitions of culture require additional characteristics beyond social learning and group specificity (see chapters in Laland \& Galef, 2009), when one is considering conservation and management implications, a broad definition of culture is most useful (Laland et al., 2009).

(Manuscript received March 2, 2010; accepted for publication April 9, 2010.) 